DOI: 10.1515/ausp-2017-0017

\title{
Marking the Foreign Word - A Case Study of Recent English Loans in Hungarian
}

\author{
Ina VISHOGRADSKA \\ St. Kliment Ohridski Sofia University (Sofia, Bulgaria) \\ Faculty of Classical and Modern Philology \\ i.vishogradska@uni-sofia.bg
}

\begin{abstract}
The work examines the most recent English borrowings in Hungarian, and it focuses on their morphophonological integration. By analysing the re-adjustment (if any) that they undergo in order to fit in the phonotactic requirements of Hungarian, it is revealed that the language employs a specific adaptation strategy. The aim is to show that by not obeying certain phonological laws in the process of perception and adapting the newly arrived loanwords, in fact, Hungarian demonstrates a tendency to mark these lexical items as foreign.
\end{abstract}

Keywords: loanword adaptation, Hungarian, phonology

\section{Theoretical background}

When a loanword penetrates the lexicon of a given language, it is usually perceived as a "stranger" - from the point of view of phonological shape, to start off with, to the ability to integrate morphologically, syntactically, and also semantically. The process of adaptation, inevitably governed by the system of the receiving language, triggers off language-specific strategies for supplementing the new loan with all the necessary equipment for functioning in the language. In the current paper, I look into a specific adaptation strategy, which - along with the phonotactic adjustment - employs a verbalizing strategy resulting in adapted form with the following structure loan form + verbalizing suffix. I examine the infringement of one basic regulation in Hungarian grammar which is registered in this process, and I aim to point at the fact that the anti-harmonic realizations are not sporadic or "flaws" in the system, rather, they carry a specific "marker"like function.

Evidence for the realization of harmonic or disharmonic processes in the words is found by examining a specific layer of the Hungarian lexicon - recent English loans. It is expected that in the course of reception of foreign words into 
a language, they are adapted and modified in accordance with the productive phonological regulations, processes, and constraints operating in the borrowing language. Hungarian, as a Finno-Ugric language with a finely developed harmonizing system, offers an appropriate framework. ${ }^{1}$ The English loanwords, a large number of which have entered the language only recently, give rich material for investigation of this particular implication of anti-harmonic processes. The data have been excerpted from etymological dictionaries and specialized literature, but due to the idiosyncrasy of the examined material, the main sources are web-based forums and life-style magazines. ${ }^{2}$

It is said that such harmonic systems can be motivated by the penetration of non-native lexical elements containing untypical vowel combinations, thus infringing some constraints in the phonotactics of the language. A general agreement is that loanwords often violate the vowel harmony observed by native roots, especially as far as the inner-root vowel configuration is concerned. Within the framework of generative phonology, descriptions of vowel harmony have predominantly been concerned with the behaviour of affixes attached to roots as opposed to the vowel "destiny" of the adapted loanword (within the stem), assuming, it seems, that it is beyond the reach of the vowel harmony regulations.

\subsection{Anti-harmonic parameters}

The phonological phenomenon known as anti-harmony is usually realized at morpheme boundary. While the combining of front and back vowels within the stem is treated as non-harmonic (cf. Siptár 1999: 297-298), if in the process of agglutination the suffix form does not comply with the harmonic feature of the vocal members of the stem, then it is a question of anti-harmonic manifestation, that is, a process opposite to the harmonizing mechanism. Anti-harmony in Hungarian is registered at certain types of stems as well as at a group of words which belong to a specific lexical stratum. This restricted number of realizations is reviewed in the academic grammars of the Hungarian language, and it is usually referred to as an exception rather than an infringement of the phonological law for harmonizing. For example, híd hídak 'bridge bridges', iszik iszom 'drinks I drink' etc., also polysyllabic haver-om/*haver-em 'my friend'. Apart from the previously mentioned non-harmonically regulated suffixation, there are some roots which trigger ambiguity in the choice of front/back vowel

1 Hungarian vowel harmony "hosts" a [+/-back] harmony and also, somewhat disputably, a [+/-round] harmony (for discussions on the status of labial harmony in Hungarian see, for example, Polgárdi and Rebrus 1998). Traditional description can be expressed with the following well-formedness statement:

In a [ ... V1 ... V2] sequence, V1 and V2 agree in frontness or in backness (based on Siptár 1999: 297-298).

2 For more details regarding the language data, please cf. Vishogradska and Banova (2013). 
allomorph, e.g. fotel-om/fotel-em 'my armchair', where the individual perception determines the use of the front/back form. The conclusion which could be drawn upon these data is that apart from the roots themselves it is possible that the suffixes are also characterized by certain ambiguity. If this stipulation is taken further, it could be generalized that the tendency of ambiguousness/ambiguity is an aspect that concerns the elements which are liable to harmonic processes. The exact constraints which determine the manifestation of ambiguity obviously vary; however, it is not impossible to trace them (which is an interesting matter requiring exhaustive investigation and is not part of the current interest).

\section{Linguistic data: manifestations of an adaptation strategy}

Apart from the well-known group of anti-harmonic roots (cf. discussion above), some other cases of anti-harmony are registered in recent borrowings from Germanic languages. These "brand new" loans have specific characteristics, which distinguish them in the lexicon strata as rather marginal, maybe still in the process of reception (there is no orthographic rule for their appearance) (Kertész 2003: 68). All this comes to clearly show that we deal with very "unstable" linguistic material from the point of view of future nativization. However, their morphosyntactic presence in Hungarian is a fact, and it reveals an interesting picture.

Anti-harmonic processes - similar to the ones found in the native lexemes are observed in earlier loanwords from German and new loanwords from English. These anti-harmonic realizations vary in the vocalic scheme: some follow the "native" anti-harmony (cf. the examples above), i.e. a root containing a front vowel receives verbalizing suffix with back vowel, whereas others reveal a more variable picture, for example, regarding the roundness of the vowel, the [ \pm labial] harmonic feature. The present work deals with some of the most recent loanwords from English, and it focuses on the forms which are adapted in Hungarian by employing a verbalizing suffix (which further receive a verbal ending, naturally). The prime interest is to trace those language mechanisms for "mending" the foreign form which do not comply with Hungarian grammar regulations (i.e. vowel harmony) - let me add, at first sight.

\subsection{Anti-harmonic schemes}

The group of brand new loans from English seems to follow a certain recurring strategy for adapting the borrowed lexemes. They predominately undergo primary or secondary morphophonological marking with the derivational verbalizing suffix -1 (-ol,-el, -öl). The process of reception in Hungarian generates forms 
which are already morphologically marked as verbs and surprisingly receive an anti-harmonic shape. Instead of just following the powerful morphophonological regulation of root vowel governing the choice of a harmonizing suffix, this loanword adaptation demonstrates a specific "behaviour", in contrast with the rules, as illustrated below.

\begin{tabular}{|c|c|}
\hline (1) Anti-harmonic ma & of the "stranger" \\
\hline source-language form & Hungarian form \\
\hline to bleed & blíd-ol \\
\hline to feed & fíd-ol \\
\hline to print & print-el \\
\hline to dance & densz-el \\
\hline to check & csekk-ol \\
\hline to flame & flém-ol \\
\hline to click & klikk-ol klikk-el \\
\hline save & szév-ol szév-el \\
\hline
\end{tabular}

(examples from Nádasdy 2001, 2005 and Kertész 2003: 62-77)

A possible explanation is the analogy mechanism to specific forms in Hungarian, namely the monosyllabic root with neutral vowel. However, there are also loans which do comply with the vowel harmony, as in the following examples:

(2) No marking of the "stranger"

source-language form Hungarian form

to net net-el

to chat cset-el

The data from (1) and (2) provoke a number of questions, among which the following interesting ones:

- Does the Hungarian language employ anti-harmony as a marker of foreign and some still in process of adaptation - lexemes?

- Does the trigger for anti-harmony lie in the root or in the suffix form?

- Is it an accidental problem or a tendency in the language?

An additional point is the fact that there are some cases where we find hesitation in the choice of suffix allomorph - cf. the last two examples in (1). Furthermore, a rather interesting manifestation is observed in several cases, namely that harmonic and antiharmonic forms co-exist in the language, but with different semantic implementation. Please, consider the examples provided below.

(3) Semantic differentiation (on harmonic $\sim$ anti-harmonic level)

source-language form $\quad$ Hungarian form

to check

(be) csekkol 'to check in'

to check

csekkel

'with cheques; fiddle/deal with cheques' 
Once verbalized, these recent loans behave according to the rules: they receive suffix forms (verbal endings in their paradigm) as the vowel harmony regulates in Hungarian, i.e. the last vowel in the stem determines the harmonizing feature of the suffix form. Consider the following examples:

\begin{tabular}{|c|c|c|}
\hline (4) source-language form & $\underline{\text { Hungarian form }}$ & 1/Sg, Pr.T.Ind. \\
\hline to bleed & blíd-ol & blíd-ol-ok \\
\hline to feed & fíd-ol & fíd-ol-ok \\
\hline to print & print-el & print-el-ok \\
\hline to dance & densz-el & densz-el-ok \\
\hline to check & csekk-ol & csekk-ol-ok \\
\hline to flame & flém-ol & flém-ol-ok \\
\hline to click & klikk-ol klikk-el & klikk-ol-ok klikk-el-ek \\
\hline to save & szév-ol szév-el & szév-ol-ok szév-el-ek \\
\hline
\end{tabular}

This group of anti-harmonic borrowings is rather dynamic, and it is still acquiring, respectively losing members. They are a challenge to describe, even more so due to the fact that the morphophonological adaptation is processed on different paths, leading to various forms after suffixation. As such, they are even more puzzling than the "native" realizations of anti-harmony. This "brand new" layer of the Hungarian lexicon is also an indicator for current phonological, phonotactic, and various other language issues and tendencies.

\subsection{Labiality - an additional marker}

A certain group of less recent loans from German or English also demonstrates an intriguing form of anti-harmony: the verbalizing process which triggers the suffixation of the lexeme generates a form which has the root and the suffix with opposite labiality features, i.e. if the root vowel is [+labial], then the suffix form is [-labial] and vice versa. Consider the following examples:

(5) Anti-harmonic marking of the "stranger" on labial line

Hungarian form
keccs-öl $(\sim$ keccsel $)$
fecc-öl
stír-öl

The labializing suffix is a surprising choice since there is no exact parallel in the Hungarian language of such anti-harmonic realizations elsewhere in the lexicon strata. Rather, a simplification of the [ \pm labial] picture is found: to [+labial] stems [-labial] suffix allomorphs are added, e.g. könyv 'book' könyvnek 'book-DAT', szólő 'grapes' szôloó-nek, 'grapes-DAT', füst 'smoke' füst-nek 'smoke-DAT'. Furthermore, a mirror image of [ \pm labiality] is found again among the Germanic verb loans. 
(6) Anti-harmonic marking of the "stranger" on labial line 2

curükk-ol $\quad{ }^{*}$ curükk-öl

gründ-ol *gründ-öl

The strange vowel configuration from (6) above is marginal, perhaps unstable. However, it does exist as a result of loan adaptation in the language, and thus such phonotactic realizations "precedent" the system. In the relevant literature, data and analysis regarding this "labial anti-harmony" are scarce also due to the fact that some of the loans were with short-term presence in the active language, and they have either disappeared or completely marginalized (Nádasdy 2005).

\subsection{The semantic aspect: an additional function?}

Among the richness of anti-harmonic realizations resulting from the adaptation strategy for verb loans in Hungarian, one specific, additional function is also registered. It seems that anti-harmony is also semantically loaded as the choice of harmonic vs anti-harmonic suffixations brings about a difference in the meaning of the adapted forms. As a result, two different lexemes are formed, as illustrated in the examples below.

(7) [+harmonic] csekkel $<$ csekk +- ol/el 'with cheques; fiddle/deal with cheques'

[-harmonic] (be) csekkol < csekk + - ol 'to check (in)'

The fact that vowel harmony implementation (by observing the regulation, or by not observing it) is not solely a phonological phenomenon, is revealed by earlier data, again in the adaptation of foreign lexemes. In the early Slavic borrowings (dating from the eleventh to the fifteenth century), we find a different scheme, which, however, again involves the function of harmonizing of the vowel stock (of the source form), in regard to root vocal structure.

(8) [+back harmonic] család 'family' < szl. челяд 'off-spring, child'

[-back harmonic] cseléd 'servant' < szl. челяд 'off-spring, child'

The above data clearly indicate that vowel anti-harmony is not merely an infringement to a Hungarian-language regulation. It is "used" by the language as a tool in the adaptation process.

A far-fetched parallel with similar semantic aspect could be found in the suffixation harmony/anti-harmony in the language (not as a result of adaptation strategy). For example, the monosyllabic szív 'to suck' is among the so-called antiharmonic roots, i.e. szív + -k '1/Sg, Pr.T.Indef.' > szívok, but *szívek 'I suck', that is, it has anti-harmonic suffixation. In the Hungarian lexicon, we find an absolute homonym of this verb: sziv 'heart', obviously with a different meaning, which has a harmonic paradigm, e.g.: szív 'heart' szív-ek 'heart-Pl'. That is, despite the identical sound shape, the two lexemes demonstrate different harmonizing behaviour. This, of course, is explained in terms of historical development of 
language laws and tendencies, predetermining the implementation of harmonizing suffixes for certain roots in Hungarian. Yet, nevertheless, the language does have such distinction which might trigger analogy schemes under certain conditions.

\section{Concluding lines}

As already pointed out above, due to the fact that this is a completely "fresh" addition to the loanword stock in Hungarian, it is more difficult to give an exhaustive definition of the set. With all that in mind, here it was attempted to give pliable answers to the three questions which were marked in the course of the presentation. In sum, it could be stated that in contrast with the native anti-harmonic roots whose description is found in academic grammars, here we encounter a different mechanism of violating vowel harmony in Hungarian.

In addition, this work would like to voice another hypothesis, based on the examination of verb adaptation strategies in the most recent borrowings: the appearance of the anti-harmonic verbalizing suffix in the process of morphophonological incorporation might be treated as a specific marker of the language, indicating the "status" of the borrowings, similar to a "red flag" for the lexicon stratum, signalling that these items have just entered the language, for example. By all means, a further detailed investigation is required in order to give a clearer answer as to whether there is some sort of secondary function of the anti-harmonic realizations.

\section{References}

Bolonyai, Agnes. 2005. English verbs in Hungarian/English Code-Switching. In James Cohen, Kara T. McAlister, Kellie Rolstad, Jeff MacSwan (eds), ISB4: Proceedings of the $4^{\text {th }}$ International Symposium on Bilingualism, 317-327. Somerville, MA: Cascadilla Press.

Bárczi, Géza. 2001. A magyar szókincs [The Hungarian Lexicon]. Budapest: Tinta Könyvkiadó.

Clemets, G. N.-Sezer, E. 1982. Vowel and Consonant Disharmony in Turkish. In Harry van der Hulst-Norval Smith (eds), The Structure of Phonological Representations, vol II. Dordrecht: Mouton de Gruyter.

Durand, Jacque. 1990. Generative and Non-Linear Phonology. London: Longman. Hulst, Harry van der-Jeroen van de Weijer. 1995. Vowel Harmony. In John A. Goldsmith (ed.), The Handbook of Phonological Theory, 495-534. Oxford: Blackwell. 
Kertész, Zsuzsa. 2003. Vowel Harmony and the Stratified Lexicon of Hungarian. The Odd Yearbook 7: 62-77.

Kiefer, Ferenc, ed. 2001. Strukturális magyar nyelvtan [Structural Grammar of Hungarian]. Budapest: Akadémiai kiadó.

Nádasdy, Ádám-Siptár, Péter. 2001. A magánhangzók [The Vowels]. In Kiefer, Ferenc (ed.), Strukturális magyar nyelvtan 2: Fonológia [Structural Grammar of Hungarian 2: Phonology], 42-182. Budapest: Akadémiai kiadó.

Rebrus, Péter-Szigetvári, Péter. 2016. Diminutives: Exception to Harmonic Uniformity. Catalan Journal of Linguistics 15: 101-119.

Rebrus, Péter-Miklós Törkenczy. 2015. Monotonicity and the Typology of Front/ Back Harmony. Theoretical Linguistics 41(1-2): 1-61.

Szépe, György. 1958. Vegyes magáhangzójú szavaink illeszkedésének kérdéséhez [On the Question of Harmonizing of Mixed Vowel Words]. Nyelvtudományi Érintkezések 17: 105-129.

Siptár, Péter. 1999. Hangtan [Phonetics]. In Katalin É. Kiss-Ferenc Kiefer-Péter Siptár (eds), Új magyar nyelvtan [New Hungarian Grammar]. Budapest: Osiris. Vishogradska-Meyer, Ina-Savelina Banova. 2013. The Native Element in 'Brand New' Loan Verbs: Adaptation Strategies in Bulgarian and Hungarian. Paper presented at the XIX International Congress of Linguists, 21-27 July 2013, Geneva. https://www.cil19.org/cc/en/abstract/contribution/667/index.html. 